\title{
Acute Care Practice in the United States: The Roles of Occupational Therapy and Physical Therapy in Early Rehabilitation
}

\author{
Suzanne E. Holm ${ }^{1,2}$, Kelly Nelson ${ }^{2}$, Angela Patterson ${ }^{2}$ \\ ${ }^{1}$ Regis University, Denver, Colorado 80221, USA; \\ ${ }^{2}$ Creighton University, Omaha, Nebraska 68178, USA
}

Received 2019-10-28; accepted 2019-12-05

DOI : $10.3724 /$ SP.J.1329.2020.03014

开放科学(资源服务) 标识码 (OSID):

\begin{abstract}
This review article describes the patterns and trends of early rehabilitation (ER), occupational therapy (OT) and physical therapy (PT), and the specific roles of rehabilitation therapists, particularly occupational therapists (OTs) and physical therapists (PTs) in acute care hospitals in the United States (U.S.). First, a broad overview of the research literature related to the consequences of bed rest and immobility is presented along with the techniques used by OTs and PTs to minimize negative outcomes and optimize function through ER. Occupation-based and mobility-focused practices are then outlined to describe rehabilitation therapy's role in decreasing readmissions and improving patient and family satisfaction. Finally, traditional OT and PT practices in acute care settings in China, including the challenges of implementing ER and the implications for contemporary practice, are discussed. ER refers to the initiation of therapy services in an expedited manner for patients who have rehabilitative, safety, or community support needs in the acute care hospital. That is, after experiencing an injury, illness, or disease, patients' occupational performance and ability to participate in activities and mobility can be improved, or prevented from worsening, with ER. The goals of OT and PT in an accelerated and fast-past hospital environment are to facilitate a patient's functional performance and outcomes to improve function recovery and to prevent further disability and loss of function. Currently in U.S., federal regulations, health care policies, financial constraints, and the demanded shortened hospital stays require therapists to be both comprehensive and efficient and to continue advancing ER practices. Early rehabilitation must be well-timed and intensive enough to bring about positive changes. Additionally, ensuring patients' active engagement and addressing therapy goals that patients and families identified as essential are imperative to achieve patients' successful transition to home or to another setting. Through ER, not only can a patient's functional abilities improve, but ER reduces the risk of undesirable and unintended health consequences. Such hospital-acquired conditions (HAC) are conditions which occur during a patient's hospitalization and are not present at admission. The risk of developing $\mathrm{HAC}$ increases if the patient is limited from active engagement in activity and mobility as a result of bed rest, immobility, or deconditioning. Systemic deconditioning, which can result from a prolonged critical illness, a trauma, or a surgery, reduces the patient's functional capacity, impairs cognitive abilities, diminishes psychological coping, and increases rates of depression and anxiety. With ER, the specific OT and PT rehabilitative interventions minimize the risk for negative health conditions, impairments, and disability while simultaneously promoting functional recovery. Specific to each rehabilitation profession's roles and responsibilities in the U.S., OTs promote the patients' occupational performance and participation in daily occupations, roles, habits, and routines. Through facilitating the patient's engagement in typical activities of daily living, OT improves patient's overall health, well-being, and independence at home and in the community. In addition to direct therapy service to patients, OTs also assess and recommend specific task and environmental modifications. Occupational therapists' intervention may focus on compensatory (i.e., facilitating occupation through modifying the task or environment) or remediation (i.e., rehabilitative) techniques for patients to achieve a greater level of independence. In PT, the emphasis is on promoting and progressing patients' mobility and movement to increase performance and to enhance function, well-being, overall health and quality of life. PTs promote optimal mobility to enable patients to achieve a greater level of independence, autonomy, and to return to previous or enhanced level of function. Any patient who has or may develop impairments, activity limitations, and participation restrictions related to musculoskeletal, neuromuscular, cardiovascular, pulmonary, and integumentary systems can be treated by PT. Therefore, PTs are well-suited to promote early rehabilitation (ER) in the acute care
\end{abstract}

引用格式:HOLM S E, NELSON K,PATTERSON A. 美国的急性医疗实践 : 作业治疗和物理治疗在早期康复中的作用 [J]. 康复学报, 2020,30(3): 240-248,封三. HOLM S E,NELSON K, PATTERSON A. Acute care practice in the United States: The roles of occupational therapy and physical therapy in early rehabilitation [J]. Rehabilitation Medicine,2020,30(3):240-248, 封三

DOI: $10.3724 /$ SP.J.1329.2020.03014 
setting. In the U.S., currently, however, acute care hospitals are not often designed to support patients and meet their intensive rehabilitation needs. Consequently, patients who require assistance with daily occupations or mobility or who have ongoing rehabilitation needs often result in relocating, or transferring to another health care facility, i.e., post-acute care, for continued recovery of medical issues and rehabilitative deficits. Multiple levels of post-acute care are available in the U.S. including skilled nursing facilities, rehabilitation hospitals, long-term acute care hospitals, nursing homes, outpatient clinics, home health, and private caregiver services. Currently, in the Chinese acute care hospital, patients have the option to stay for an extended period of time which provides the opportunity for OTs and PTs to provide multiple rehabilitation visits. Typically, the outcomes of OT and PT services are to restore physical mobility, increase active range of motion, and improve function in order for the patient to return home with family. It seems, due to the Chinese culture, tradition and custom, less emphasis is on improving independence with self-care activities. It is expected that family members take on the responsibilities to provide care to a family member who is ill or has disabilities. As such, in China there is typically a supportive family dynamic, meaning the family is present daily during rehabilitative intervention, helping provide therapeutic exercises and physical agent modalities for their loved ones. The burden of care on the family members worsens at discharge, especially if the patient and family have not received therapy or patient education to improve the patient's function and independence. Currently, the profession of rehabilitation including occupational therapy and physical therapy in China is in an excellent position of growth and advancement. Understanding the unique roles of OT and PT in acute care from an international perspective will improve global health not only through rehabilitative services, but also through focusing on health and wellness for the patient, family, and community. Early rehabilitation in the acute care setting is an effective way to improve the health and well-being of patients and enable them to return to their home and community in a timely manner. OTs and PTs play instrumental roles in early rehabilitation in the acute care settings.

KEY WORDS hospitals rehabilitation; occupational therapy; physical therapy; bed rest; clinical decision-making

In the United States (U.S.) acute care hospital system, early rehabilitation (ER) refers to the initiation of therapy services in an expedited manner for patients who have rehabilitative, safety, or community support needs. The goals of occupational therapy (OT) and physical therapy (PT) in this accelerated and fast-past hospital environment are to facilitate a patient's functional performance and outcomes to improve recovery and to prevent further disability and loss of function. In the U.S., ER must be well timed, intensive enough to make positive changes, require active engagement of the patient, and address the goals that the patient and family identified as important.

\section{Factors influencing early rehabilitation in the U.S.}

Multiple external factors shape and influence how and when OT and PT services are provided in the acute care hospital. Specific factors that influenced the initiation of ER included changes in healthcare policies, penalties associated with certain outcomes, and patients' limited length of stay (LOS). Policies require healthcare providers and the hospitals to reduce the incidence of preventable hospital-acquired conditions (HAC) like urinary tract infection and pneumonia that can result in increased co-morbidities or even mortality ${ }^{[1-2]}$. Financial penalties exist for hospital readmissions (i.e., patient returns to the hospital within 30 days of leaving the hospital) and also when patients experience adverse events which include unintended injury caused by medical care or lack of care ${ }^{[3]}$. Finally, the average LOS in all U.S. hospitals declined from 9.1 days in 1990 to 5.5 days in $2014^{[4]}$, limiting the time for rehabilitation. Hospitals support ER by prompt referrals to OT and PT to address a patient's rehabilitation and social needs, reduce the risk for hospital readmissions and HAC, and enable a successful return to the community.

With limitations on LOS, U.S. acute care hospitals are not designed to support patients for intensive therapy needs over extended days. OT and PT are also required to assess a patient's ability to successfully leave the hospital (i.e., discharge) to return home. If the patient requires functional or mobility assistance or has ongoing rehabilitation needs, then the patient may transfer to another health care facility for continued recovery of medical and rehabilitative needs. Multiple levels of post-acute care are available in the U.S. and include skilled nursing facilities, rehabilitation hospitals, long-term acute care, nursing homes, outpatient clinics, home health therapies, and private caregivers.

\subsection{Early rehabilitation practice}

ER can minimize the risk of a person's loss of function due to hospitalization. The International Classification of Functioning, Disability, and Health model defines function as not only changes in the function and structure of a person's body, but also how activity limitations, participation restrictions, and environmental barriers contribute to a person's overall functional status along a continuum ${ }^{[5]}$. Providing effective rehabilitation services is part of the responsibility of a health care system or service to address the needs of sick people ${ }^{[6]}$ with the goal of helping people remain as independent and productive as possible.

\subsection{Benefits of early rehabilitation}

The standard of care for ER includes a physician's 
referral for therapy to be addressed within 24 hours especially for patients admitted with complex medical and functional needs. Referrals may be prompted by a patient's poor mobility status upon admission ${ }^{[7]}$, care plan ${ }^{[8]}$, or diagnostic category ${ }^{[9]}$, or as determined by other health care providers. Types of patients and situations appropriate for ER are outlined in Table 1.

Table 1 Types of situations appropriate for early rehabilitation

\begin{tabular}{|c|c|c|}
\hline Patient situation & Early rehabilitation to increase functional outcomes & Examples of diagnoses \\
\hline $\begin{array}{l}\text { Post-neurological or significant } \\
\text { surgical event }\end{array}$ & Increased intensity, frequency, and duration of service & $\begin{array}{l}\text { Cerebrovascular accident; Post lower } \\
\text { extremity amputation }\end{array}$ \\
\hline $\begin{array}{l}\text { Post-elective joint surgery with } \\
\text { expected discharge in } 1-5 \text { days }\end{array}$ & Begin therapy on day of surgery or following day & $\begin{array}{l}\text { Joint replacement; lumbar or cervical } \\
\text { fusion }\end{array}$ \\
\hline $\begin{array}{l}\text { Frail elderly; acute on chronic } \\
\text { illness; fall or injury }\end{array}$ & $\begin{array}{l}\text { Safety, cognition, ADL and mobility status to deter- } \\
\text { mine if patient can return to prior level of function } \\
\text { and situation }\end{array}$ & $\begin{array}{l}\text { History of rheumatoid arthritis, falls, } \\
\text { diabetes, pneumonia, coronary heart } \\
\text { failure }\end{array}$ \\
\hline $\begin{array}{l}\text { Complex health conditions; tra- } \\
\text { uma; neurological conditions } \\
\text { requiring intensive medical care }\end{array}$ & $\begin{array}{l}\text { Minimize complications from immobility and bed rest } \\
\text { and promote upright posture }\end{array}$ & $\begin{array}{l}\text { Cardiopulmonary conditions; traumatic } \\
\text { brain or a spinal cord injury; ventilator } \\
\text { support }\end{array}$ \\
\hline
\end{tabular}

Improving functional abilities through ER can reduce the incidence of hospital-acquired conditions. A $\mathrm{HAC}$ is a condition obtained while the patient was hospitalized and was not present at admission. With $\mathrm{HAC}$, the risk of developing complications increases with bed rest, immobility, and deconditioning. Examples of HAC include falls and fall-related trauma; infection; catheter-associated urinary tract infection; Stage III and IV pressure injuries; and deep vein thrombosis or pulmonary embolism following a joint replacement ${ }^{[1-2]}$. Through ER, the risks and consequences associated with immobility and $\mathrm{HAC}$ can be minimized.

\subsection{Specialized care environments}

ER is essential for the most vulnerable patients who require intensive nursing and medical care and are typically in specialized care environments. Usually, adult patients are treated in the intensive care unit (ICU) and high-risk infants (e.g., premature babies) are treated in the neonatal intensive care unit (NICU). Practice guidelines outline the roles and benefits of OT and PT ER in the NICU ${ }^{[10-12]}$.

In the ICU, patients are very ill, have sustained multiple trauma or significant neurological injury, or require life-saving measures (e.g., surgery, tracheal intubation, ventilator support). ICU PT progressive mobility programs appear to help patients reduce the number of days spent on a ventilator, decrease the overall LOS, improve prognosis related to secondary complications, and save cost ${ }^{[13]}$. Many research studies highlight the benefits of using OT in the ICU as part of team approach to patient care ${ }^{[14.17]}$, especially to facilitate functional cognition and a return to familiar daily activities.

\section{Bed rest and immobility}

Doctors may recommend bed rest, or being restricted to bed, to support medical stability, reduce pain, or to promote cardiac-pulmonary conservation. Some diagnoses associated with bed rest include high blood pressure, myocardial infarction, pulmonary embolism, obstetric complications, extensive burns, and skin grafts. Limited bed rest is acceptable for some conditions or to assess the effectiveness of medications or procedures, but research has linked prolonged bed rest, immobility, and limited movement with preventable secondary complications and harmful consequences, which questions the efficacy of the treatment for most conditions ${ }^{[18-23]}$.

\subsection{Complications}

Systemic deconditioning reduces functional capacity, impaired cognitive abilities, reduces psychological coping, and increases rates of depression and anxiety, which are complications of immobility. Pain and discomfort may contribute to immobility and maybe a secondary consequence of bed rest, especially if a pressure injury has developed. Short-term bed rest in the elderly (e.g., age 65 or older) contributes to diminished strength in knee extension, decreased walking speed, reduced ability to perform sit to stand, and reduced fitness levels, which are linked to the inability to perform expected activities of daily living ${ }^{[24]}$ and mobility. Deconditioning as a result of bed rest or immobility is a common side-effect and impedes returning to mobility and self-care routines ${ }^{[25-26]}$. A preventative approach to minimize the side effects of bed rest and immobility may be prioritized over potential risks associated with ER, especially in the ICU ${ }^{[27-28]}$. Bed rest and immobility are associated with a negative cascade of changes to behavioral, integumentary, gastrointestinal, musculoskeletal, cardiovascular, and pulmonary systems. Table 2 lists the effects of immobility on major organ systems ${ }^{[29]}$.

2.1.1 Cognitive and psychological systems Individuals restricted to bed rest experience sensory deprivation which can result in unintended cognitive and psychological impairments like disorientation, mood disorders, and delirium. Immobility contributes to a decline in self-image and empowerment, isolation, and increase dependency on others ${ }^{[30]}$. Disengagement in 
Table 2 Effects of immobility on organ systems

\begin{tabular}{ll}
\hline \multicolumn{1}{c}{ Organ system } & \multicolumn{1}{c}{ Effects of immobility } \\
\hline Musculoskeletal & Weakness, muscle, and joint contracture, osteoporosis, exercise intolerance \\
Cardiovascular & Deconditioning, orthostatic hypotension, increased risk for thrombus formation \\
Respiratory & Hypoventilation, atelectasis, increased risk for pneumonia \\
Metabolic/Endocrine & Decreased metabolic rate, impaired protein and fat metabolism, bone loss \\
Integumentary & Pressure ulcers, systemic infection \\
Neurological/Psychological & Confusion, sensory deprivation, depression, impaired coping \\
Gastrointestinal/Urologic & Constipation, reflux, urinary retention, reduced peristalsis \\
\hline
\end{tabular}

daily routines, roles, and responsibilities can result in diminished goal-directed behaviors and increase a person's sense of learned helplessness ${ }^{[31-32]}$. Immobility can increase the anticipation and sensitivity to pain and avoidance of movement, creating a pain cycle that increases psychological stressors and fear of movement ${ }^{[33]}$.

2.1.2 Cardiovascular system Prolonged bed rest may result in orthostatic hypotension due to the autonomic nervous system's inability to regulate blood volume and pressure. The patient's overall heart rate and central blood volume increases. Hypovolemia is the result of diuresis and places the patient at increased risk for deep vein thrombus (DVT) formation due to venous stasis and hypercoagulability.

2.1.3 Pulmonary system Respiratory function is compromised, resulting in decreased effective inspiration and expiration. Restricted ribcage expansion may result in oxygen desaturation, increased carbon dioxide levels, and viscosity of secretions. The ciliary function is less effective, the cough reflex is reduced, and people are at greater risk for developing respiratory infections, like pneumonia ${ }^{[30]}$. The incidence of hospitalacquired pneumonia increases for those who are elderly, male sex, and who have multisystem organ failure [34]

2.1.4 Musculoskeletal system The musculoskeletal system depends on movement against gravity with vertical and compressive forces on weight-bearing bones to function and respond normally. Ten days of bed rest results in decreased aerobic capacity and endurance, impaired lower body strength, and difficulty engaging in expected physical activity ${ }^{[35]}$. Musculoskeletal deterioration begins within 6 to 48 hours of bed rest; in one week, there is a $30 \%$ to $40 \%$ loss of muscle strength, especially for the very ill ${ }^{[22]}$. Disuse osteoporosis may develop, especially for those who sustained a neurological injury, increasing the risk for fractures ${ }^{[36]}$.

2.1.5 Endocrine, metabolic and immune systems Immobility alone can alter insulin response and anti-inflammatory activities of macrophages. In five days of bed rest, adults experienced reduced overall immune response and insulin activity ${ }^{[37]}$. The function of the lymphatic system is reduced, resulting in edema. Endocrine function and metabolic rates are impaired, which increases the risk for protein breakdown and excretion of essential electrolytes.
2.1.6 Integumentary system Pressure injuries are localized damage to the skin and underlying soft tissue usually over a bony prominence or related to medical or other devices ${ }^{[38]}$, as a result of intense or prolonged pressure and shear forces. The tolerance of soft tissue for pressure and shear may be affected by "microclimate, nutrition, perfusion, co-morbidities, and condition of the soft tissue" ${ }^{[38]}$. Specifically, pressure injuries are related to inadequate nutritional status ${ }^{[39]}$, poor skin hygiene and the presence of medical devices such as nasal oxygen tubes, casts/splints, and airway masks ${ }^{[40]}$.

\section{Occupational therapy}

A person's culture and values determine the importance of individual independence (i.e., the freedom to make choices), self-sufficiency (i.e., relying on one's abilities), and self-determination (i.e., controlling one's life). Independence is a core tenant and value in the occupational therapy profession ${ }^{[41]}$. Occupation is the central concept since humans are occupational beings ${ }^{[42-43]}$. OT encourages the performance of and participation in everyday occupations, roles, habits, and routines to promote health, well-being, and independence at home and in the community ${ }^{[447]}$.

\subsection{Occupational therapy process}

Activities of daily living (ADLs) are considered, "fundamental to living in a social world; they enable basic survival and well-being" ${ }^{[48]}$. The OT process includes the assessment of a person's current occupational status and profile, prior level of function with ADLs and instrumental activities of daily living (IADLs), goal setting related to the discharge plan, and interventions using valued occupations.

Through skilled observation and assessment tools, occupational therapists (OTs) assess current functional status related to self-care, functional transfers, cognition, psychological well-being, vision and hearing, visual perceptual skills, coordination, balance, upper and lower extremity functional status, functional endurance, and neuromuscular status ${ }^{[49-50]}$. IADL performance assessments may be completed for patients returning to those roles. Common acute care outcome and formalized assessments include the Cognistat, Montreal Cognitive Assessment, Modified Barthel Index, and Functional Independence Measure ${ }^{[50-53]}$. Patient-centered goals are formulated to address occupational deficits and facilitate patient and family training 
and education.

Additionally, the OTs determine the need for task and environmental modifications. Interventions may focus on compensatory (i.e., facilitating occupation through modifying the task or environment) or remediation (i.e., rehabilitative) techniques to achieve a greater level of independence. Additionally, treatment can address fall risk, medication management, and home safety recommendations ${ }^{[5455]}$.

\subsection{OT role in minimizing deconditioning and promoting early rehabilitation}

OTs have a responsibility to address preventable deconditioning and related side-effects for acute care patients. Functional occupations and ADLs are integrated as part of the patient's treatment plan; these activities are used to prevent deconditioning and minimize functional decline ${ }^{[56-57]}$. Common OT acute rehabilitation interventions used to minimize deconditioning and maximize performance include ADL training, light meal preparation, cognition, safety awareness, and remediation, and functional mobility ${ }^{[57-58]}$. OT ER encourages activity in the hospital room while the patient is seated on the edge of bed or in a chair; promotes participation in routines by ensuring adequate sensory input (e.g., lighting, visual and hearing aids, noise reduction); reduces the risk for aspiration and pneumonia by optimizing positioning to ensure safe swallow and restore nutrition intake; and promotes meaningful occupations, social interaction, and leisure activities ${ }^{[59]}$. Patients achieve strength and range of motion naturally by engaging in structured ADL practice, which engages familiar neurological pathways and provides a sense of accomplishment and progress. The optimal recovery of the nervous system function requires OT to provide the integration of novel and challenging occupations beyond strengthening or exercises ${ }^{[60]}$.

\subsection{OT and reducing readmissions}

Diminished functional status and not addressing ADLs are correlated with hospital readmissions [61] $\mathrm{ADL}$ assessment is critical since hospitalization is often associated with ADL dysfunction. Patients who leave the hospital with unmet ADL needs or unaddressed functional and social needs are more likely to be readmitted to the hospital within one year ${ }^{[61-62]}$. The risk increases for the elderly where 1 in 4 patients return home with $\mathrm{ADL}$ deficits ${ }^{[61]}$. Reducing the risk for readmission requires an OT assessment of functional status and treatment to address ADL impairments ${ }^{[55]}$. In one study, researchers concluded that added spending on OT treatments for patients with certain health conditions (i.e., heart failure, pneumonia, and acute myocardial infarction) resulted in a statistically significant reduction in readmission rates ${ }^{[62]}$. Finally, elderly patients who received OT acute care services reported greater confidence in the ability to complete ADLs and an improved sense of well-being with improved patient and family satisfaction ${ }^{[63]}$.

\section{Physical therapy}

The PT profession in the U.S. is grounded in the concept of promoting mobility among people of all ages. Physical therapists (PTs) are considered "movement experts" by the American Physical Therapy Association (APTA) and are described as "health care professionals who help individuals maintain, restore, and improve movement, activity, and functioning, thereby enabling optimal performance and enhancing health, well-being, and quality of life" ${ }^{[64]}$. The slogan of APTA is "move forward-physical therapy brings motion to life" ${ }^{65]}$. Serving people of all ages, PTs treat anyone who has or may develop impairments, activity limitations, and participation restrictions related to musculoskeletal, neuromuscular, cardiovascular, pulmonary, and integumentary systems ${ }^{[64]}$. Following the Guide to Physical Therapist Practice, PTs analyze impairments, identify deficits in activities and participation and provide safe, effective, and efficient interventions to restore patient function ${ }^{[66]}$. Additionally, the focus is to promote optimal mobility to achieve independence, autonomy, and return to a previous or enhanced prior level of function. Therefore, PTs are well-suited to promote ER in the acute care setting.

\subsection{Physical therapy process}

In the acute care setting, key activities addressed by PT to support ER include helping patients and their families navigate the health care system; reducing secondary complications; ensuring maximal levels of mobility and physical performance; and communicating, collaborating, and advocating between all members of the interprofessional health care team ${ }^{[67]}$. Specifically, PTs assess and treat issues related to strength, range of motion, endurance, airway clearance, balance, coordination, gait or wheelchair mobility, transfers and transitions, posture, skin integrity, and pain ${ }^{[68]}$.

In the acute care hospital, PTs treat patients in a one-on-one setting, typically within a patient's room and in adjacent hallway spaces, promoting progressive out of bed, chair, and room activities. PT services focus on function, mobility, and safety ${ }^{[67]}$. The PTs ensure medical stability through vital signs assessment while examining available joint range of motion, postural control, balance abilities, cardiopulmonary endurance, muscular strength and endurance, and functional mobility involving transfers and transitions and gait on level surfaces and stairs.

A plan of care includes goals related to the progression of mobility-based exercises and activities while the patient remains in the hospital ${ }^{[68]}$. If the patient has specific and unique needs (e.g., open wound, severe pain, or is using a ventilator), PTs may use specialty interventions and tools such as biophysical agents and modalities to promote mobility and function. Education to the patient, family, and other care providers to supplement the carryover of new skills may include exercise programs or walking with the patient in the hallway. 


\subsection{PT role in minimizing deconditioning}

A component of ER includes early mobility, the onset of walking or pre-walking skills within 72 hours of admission ${ }^{[69]}$. Wood and colleagues ${ }^{[70]}$ describe it as the performance of walking or pre-walking skills at least twice per day while in the hospital. Pre-walking skills may include performing sit to stand transfers, standing for endurance, weight-shifting or reaching in standing, and marching in place. Increased mobility and higher levels of activity align well with the Institute for Healthcare Improvement's "Quadruple Aim" ${ }^{[71]}$ in healthcare: improving quality of care; improving patient experience of care while decreasing per capita cost; and improving health care provider satisfaction ${ }^{[72]}$. The acute care PT is well positioned to help patients avoid negative consequences of immobility and the effects on body systems. Pashikanti and Von ${ }^{[73]}$ found the more mobile a patient was while in the hospital, the greater improvements in functional mobility and the shorter the LOS. Additional benefits of early and frequent mobility include improved quality of life, reduced anxiety and depression, improved patient satisfaction, reduced pain, and reduced costs of care ${ }^{[74]}$.

Older adults are at a higher risk for immobility in the acute care environment. In one study of hospitalized elderly, patients spent 17 hours per day in bed, 5.1 hours per day in a chair or a sitting position, and less than 1 hour per day standing or walking ${ }^{[75]}$. Similarly, Mudge et al ${ }^{[76]}$ identified that more than $50 \%$ of awake time was spent in bed; $33 \%$ of time in a chair; and less than $10 \%$ of time standing, walking or wheeling (e.g., mobility using a wheelchair). Compared to activity patterns for older adults living in their homes, hospital mobility is approximately five times less active than the person would be at home ${ }^{[77]}$.

\subsection{PT and promoting early rehabilitation and outcomes}

Besides a focus on the older adult population, it may be valuable to explore the role of the PT in ER for people with specific health conditions. Malone et al. ${ }^{[78]}$ studied patients' post-joint replacement and found better outcomes among those who walked within 24 hours of surgery. Other conditions with positive outcomes related to early mobility included those with pelvic or spinal injuries and those with acute neurological conditions. In general, research findings support the recommendation for patients to engage in a progressive mobility program guided by PTs multiple days per week ${ }^{[79-80]}$.

Regardless of the acute care patient population, PTs are increasingly called upon to select, use, and interpret findings from high fidelity outcome measures. Standardized tests and outcome measures are reported to enhance clinical decision making, allow quantification of patient change between treatment sessions, facilitate communication between health care providers, and improve efficiency of practice ${ }^{[81-84]}$. A best prac- tice finding recommends that all acute care PTs use standardized tests and outcome measures when at all possible, due to improved perceptions of clinical decision making as well as enhanced quantification of patient improvement and for optimal tracking across the continuum of care ${ }^{[85]}$. Common assessments related to balance and functional mobility included the Timed Up and Go ${ }^{[86]}$; the Six Minute Walk Test ${ }^{[87]}$; and the Performance Oriented Mobility Assessment ${ }^{\left[{ }^{86]} \text {. The }\right.}$ APTA Edge Task Force ${ }^{[88]}$ supports these assessments, especially to predict fall risk and safety.

\section{Acute care case study}

A case study will highlight the roles of OT and PT in the acute care setting. The patient is an elderly female who will undergo elective hip joint replacement surgery or total hip arthroplasty (THA) using a posterior approach. Patient has experienced increased hip pain over the past year. She lives alone in a 1-level home with 3 stairs with a rail to enter, does not receive family assistance for day-to-day tasks, and is independent with medication management, ADLs, IADLs, and mobility without an assistive device. She receives assistance from family and friends for driving and community access; she has never driven. The patient's goal is to return home. The family is agreeable to assist patient with any care required. After surgery, referrals for OT and PT evaluation and treatment for "post-op Day 0" (day of surgery) as tolerated received. Patient has posterior hip precautions (PHP) and will be instructed to avoid excess hip flexion, adduction, or internal rotation and maintain weight-bearing (WB) restrictions of no more than $50 \%$ on surgical leg. OT and PT functional evaluations found intact UE for strength, movement, coordination; minimal cues for working memory/new learning; no visual or hearing deficits, no history of falls or balance deficits. Refer to Table 3 to view an illustration of the progression of OT and PT ER and patient care from admission to discharge.

\section{OT and PT acute care practice in China}

The following perspectives on early rehabilitation in acute care practice in China are derived from anecdotal experience of U.S. OT practitioners who have multiple experiences visiting and consulting on rehabilitation services in Chinese hospitals. From traditional Chinese medicine perspective, the priority for a Chinese patient following an injury, illness, or onset of disease is to attain a balance in a person's "qi" ${ }^{89}$. Depending on the specific circumstance of the patient, achieving a well and healthy "qi" may take some time. Waiting for well achieved qi before starting rehabilitation may lose some critical time for patients. A delay in the initiation of rehabilitative services may also be due to some cultural and traditional beliefs, availabili ty and cost of OT and PT services. Evidence of effective rehabilitation outcomes in China is typically the 
Table 3 Acute care case study: OT and PT interventions during acute care stay

\begin{tabular}{|c|c|c|}
\hline Day & OT & PT \\
\hline $\begin{array}{l}\text { Post-op } \\
\text { Day } 0\end{array}$ & - OT deferred due to patient fatigue and pain & $\begin{array}{l}\text { - Evaluation and treatment } \\
\text { - Lower extremity exercises in bed } \\
\text { - Bed mobility } \\
\text { - Sit at edge of bed } \\
\text { - Review of hip precautions }\end{array}$ \\
\hline Day 1 & $\begin{array}{l}\text { - Evaluation and first treatment } \\
\text { - Bed to chair transfers } \\
\text { - ADL education } \\
\text { - Adaptive equipment (AE) training elevated toilet seat, hand- } \\
\text { rails, reacher, sock aide at walker level } \\
\text { - Toileting with AE } \\
\text { - Review of hip precautions and weight bearing status (WBS) }\end{array}$ & $\begin{array}{l}\text { - Gait in room with walker } \\
\text { - Bed to chair transfers } \\
\text { - Bed mobility } \\
\text { - Lower extremity exercise program in sitting and stand- } \\
\text { ing (on non-operative leg only) } \\
\text { - Review of hip precautions and WBS }\end{array}$ \\
\hline Day 2 & $\begin{array}{l}\text { - Lower body dressing with AE } \\
\text { - Toileting and hygiene with AE } \\
\text { - Shower transfers and bathing with AE } \\
\text { - Ambulation in kitchen area for snack or drink with walker } \\
\text { - Review of hip precautions and WBS }\end{array}$ & $\begin{array}{l}\text { - Gait training in hall with walker } \\
\text { - Trial cane for gait } \\
\text { - Increase sitting and standing lower extremity exercises } \\
\text { - Review of hip precautions and WBS }\end{array}$ \\
\hline Day 3 & $\begin{array}{l}\text { - Family training and education } \\
\text { - Toilet, hygiene, and dress with AE and cane } \\
\text { - Tub/shower transfer with tub transfer bench/shower chair } \\
\text { - Simple meal prep in kitchen area }\end{array}$ & $\begin{array}{l}\text { - Family training and education } \\
\text { - Gait on steps with cane } \\
\text { - Gait for household distances with cane } \\
\text { - Car transfer } \\
\text { - Sitting and standing lower extremity exercises } \\
\text { - Standing balance activities } \\
\text { - Test of hip precautions and WBS }\end{array}$ \\
\hline \multicolumn{3}{|c|}{$\begin{array}{l}\text { Patient to discharge home on day } 3 \text { after family demonstrates safety and independence with training and education. Patient } \\
\text { functioning at supervision level of assist for ADL. Medical and rehabilitation team report patient is medically stable and may return } \\
\text { home with family who will provide } 24 \text {-hour supervision and assist for IADLs. OT and PT recommend ongoing OT and PT through } \\
\text { home health services. Patient will have her first visit the day after discharge to work on independence, safety, and ongoing } \\
\text { rehabilitation education. }\end{array}$} \\
\hline
\end{tabular}

result of a stay in an acute rehabilitation level 2 or level 3 hospital facility compared with a stay in the acute care setting.

In the Chinese acute care setting, patients typically stay for an extended period, which allows for multiple rehabilitation visits. Once OT and PT are initiated, the goal of treatment is to restore physical mobility and function. Rehabilitation for self-care activities is less of a priority over active range of motion and mobility to return to home. In both the U.S. and China, it is important to involve the family in the rehabilitation process. China has a much more supportive family dynamic, meaning the family is present daily during treatment and helps to provide therapeutic exercises and physical agent modalities for the patient. With the family support in treatment, patients experience an increase in treatment time and a decrease in denials for therapy participation. Chinese patients are often readmitted to the hospital after a stay-at-home to receive additional medical services including rehabilitation. To receive additional OT and PT services, a patient's family will bring the patient back to the hospital for another inpatient stay. The continuum of care to other discharge settings beyond home currently is not always available in China.
Despite the differences in the provision of treatment and the overarching medical systems in the U.S. and China, there are lessons to be learned from both western and eastern perspectives. The effects of immobility on the body systems are not altered by ethnicity. Benefits of early rehabilitation in an acute care hospital will have long-term benefits and support the rehabilitation potential of every patient. Understanding the unique roles of OT and PT in acute care from an international perspective will improve global health. Chinese rehabilitation therapy has been identified as a profession since the $1980 \mathrm{~s}$. The separation of OT and PT as unique professions began around 2000, with the last decade experiencing a significant increase in development. The relatively young age of OTs and PTs in China may provide a vibrant perspective on the future growth of the profession ${ }^{[90-91]}$. Many OTs and PTs are educated at Traditional Chinese Medicine (TCM) universities which support various rehabilitation techniques such as manual therapy and therapeutic exercises. International OTs and PTs can learn greatly from the China acute care practices of combining Eastern practices into a Western approach of rehabilitation ${ }^{[90]}$. 


\section{References}

[1] Centers for Medicare and Medicaid Services. Hospital readmissions reduction program [EB/OL]. (2012-10-01) [2018-12-01]. https://www.cms.gov/medicare/quality-initiatives-patient-assessment-instrum- ents/value-based-programs/hrrp/hospital-readmission-reduction-program.html.

[2] Centers for Medicare and Medicaid Services. Hospital-acquired conditions $[\mathrm{EB} / \mathrm{OL}] .(2008-07-31)[2018-12-20]$. https:/www $\mathrm{cms}$.gov/medicare/medicare-fee-for-service-payment/hospitalacqcond/hospital- acquired_conditions.html.

[3] Agency for Healthcare Research and Quality. Adverse events, near misses, and errors [EB/OL]. (2019-09-10) [2019-10-01]. https: //psnet.ahrq.gov/primers/primer/34/Adverse-Events-Near-Missesand-Errors.

[4] American Hospital Association. Hospital admissions, average length of stay, outpatient visits, and outpatient surgery, by type of ownership and size of hospital: United States, selected years 1975-2014 [EB/OL]. (2016-06-28) [2019-09-20]. https://www. cdc.gov/nchs/data/hus/2016/082.pdf

[5] World Health Organization. Towards a common language for functioning, disability, and health: The international classification of functioning, disability, and health $[\mathrm{EB} / \mathrm{OL}]$. (2002-0515) [2019-09-15]. https:/www.who.int/classifications/icf/icfbeginne- rsguide.pdf

[6] Acute Care Research Collaborative. Health systems and services: The role of acute care $[\mathbf{J}]$. Bull World Health Organ, 2013,91 (5): 386-388.

[7] KAUR S, SINGH A, TEWARI M K, et al. Comparison of two intervention strategies on prevention of bedsores among the bedridden patients: A quasi-experimental community-based trial $[\mathbf{J}]$. Indian J Palliat Care, 2018,24 (1): 28-34

[8] THOMAS J, MILLER P, SILAJ A, et al. Application of physiotherapy outcome measures to the managed care model $[\mathbf{J}]$. Physiother Can, 1994, 46(4): 260-265.

[9] DORE D. Effect of the medicare prospective payment system on the utilization of physical therapy $[\mathbf{J}]$. Physical Therapy, 1987, 67(6): 964-966

[10] Occupational Therapy's Role in the Neonatal Intensive Care Unit $[\mathrm{J}]$. Am J Occup Ther, 2018, 72 (S2): 7212410060

[11] ROSS K, HENNY E, CONNER S, et al. Occupational therapy, physical therapy and speech-language pathology in the neonatal intensive care unit: Patterns of therapy usage in a level IV NICU [J]. Res Dev Disabil, 2017, 64: 108-117.

[12] SWEENEY J K, HERIZA C B, BLANCHARD Y. Neonatal physical therapy. Part 1: Clinical competencies and neonatal intensive care unit clinical training models $[\mathbf{J}]$. Pediatr Phys Ther, 2009, 21 (4): 296-307.

[13 ] RONNEBAUM J A, WEIR J P, HILSABECK T A. Earlier mobilization decreases the length of stay in the intensive care unit $[\mathrm{J}]$. J Acute Care Phys Ther, 2012, 3 (2): 204-210.

[14] DINGLAS V D, COLANTUONI E, CIESLA N, et al. Occupational therapy for patients with acute lung injury: Factors associated with time to first intervention in the intensive care unit $[\mathbf{J}]$. Am J Occup Ther, 2013, 67 (3): 355-362.

[15] O'BRIEN L, BYNON S, MORARTY J, et al. Improving older trauma patients' outcomes through targeted occupational therapy and functional conditioning $[\mathbf{J}]$. Am J Occup Ther, 2012, 66 (4): 431-437.

[16] POHLMAN M C, SCHWEICKERT W D, POHLMAN A S, et al. Feasibility of physical and occupational therapy beginning from initiation of mechanical ventilation $[\mathbf{J}]$. Crit Care Med, 2010, 38(11): 2089-2094.

[17] SCHWEICKERT W D, POHLMAN M C, POHLMAN A S, et al. Early physical and occupational therapy in mechanically ventilated, critically ill patients: A randomised controlled trial $[\mathbf{J}]$. The Lancet, 2009, 373: 1874-1882.

[18] ALLEN C, GLASZIOU P, DEL MAR C. Bed rest: A potentially harmful treatment needing more careful evaluation $[\mathbf{J}]$. The Lancet, 1999,354 (9186): 1229-1233.

[19] BROWER R G. Consequences of bed rest $[\mathbf{J}]$. Crit Care Med, 2009, 37 (10): S422-S428.

[20] CONVERTINO V A, BLOOMFIELD S, GREENLEAF J E. An overview of the issues: Physiological effects of bedrest and restricted physical activity [J]. Med Sci Sports Exerc, 1997, 29 (2): $187-190$.
[21 ] FRENCH L. Bed rest ineffective as therapy [J]. J Fam Pract, 2000, 49(1): 9-10.

[22] PARRY S M, PUTHUCHEARY Z A. The impact of extended bedrest on the musculoskeletal system in the critical care environment $[\mathbf{J}]$. Extrem Physiol Med, 2015, 4: 16.

[23] WINKELMAN C. Bedrest in health and critical illness: A body systems approach [J]. AACN Advanced Crit Care, 2009, 20 (3): 254-266.

[24] COKER R H, HAYS N P, WILLIAMS R H, et al. Bed rest promotes reductions in walking speed, functional parameters, and aerobic fitness in older, healthy adults $[\mathbf{J}]$. J Gerontol A Biol Sci Med Sci, 2015, 70 (1): 91-96.

[25] BELL K R. SHENOUDA C N. Complications associated with immobility [M]//ZASLER N D, KATZ D I, ZAFONTE R D. Brain injury medicine: principles and practice. 2nd ed. New York: Demos Medical Publishing, 2013: 810-820.

[26] HALAR E M. BELL K R. Physical inactivity: Physiological and functional impairments and their treatments [M]//FRONTERA W R (Ed.), DeLisa's Physical Medicine \& Rehabilitation: Principles and practice. 5 th ed. Philadelphia, PA: Lippincott Williams \& Wilkins, 2010: 1249-1272.

[27] HODGSON C L, STILLER K, NEEDHAM D M, et al. Expert consensus and recommendations on safety criteria for active mobilization of mechanical ventilated critically ill adults $[\mathrm{J}]$. Crit Care, 2014, 18 (6): 658

[28 ] LI Z, PENG X, ZHU B, et al. Active mobilization for mechanically ventilated patients: A systematic review $[\mathbf{J}]$. Arch Phys Med Rehabil, 2013, 94(3): 551-561.

[29] Early mobility and rehabilitation. Occupational therapy in acute Care $[\mathrm{M}]$. 2nd ed. Bethesda, MD: AOTA Press, 2017: 664

[30] NIGAM Y, KNIGHT J, JONES A. Effects of bedrest 3: Musculoskeletal and immune systems, skin and self-perception $[\mathbf{J}]$. Nurs Times, 2009, 105 (23): 18-22.

[31] LIPNICKI D M. GUNGA H C. Physical inactivity and cognitive functioning: Results from bed rest studies $[\mathbf{J}]$. Eur J Appli Physiol, 2009, 105 (1): 27-35

[32] LIPNICKI D M, GUNGA H C, BELAVY D L, et al. Bed rest and cognition: Effects on executive functioning and reaction time [J]. Aviat Space Environ Med, 2009, 80 (12): 1018-1024.

[33] WU X, LI Z, CAO J, et al. The association between major complications of immobility during hospitalization and quality of life among bedridden patients: A 3-month prospective multi-center study [J]. PLoS One, 2018, 13 (10): e0205729.

[34] PASSARO L, HARBARTH S, LANDELLE C. Prevention of hospital-acquired pneumonia in non-ventilated adult patients: a narrative review $[\mathbf{J}]$. Antimicrob Resist Infect Control, 2016, 5: 43.

[35] KORTEBEIN P, SYMONS T B, FERRANDO A, et al. Functional impact of 10 days of bed rest in healthy older adults $[\mathbf{J}]$. J Gerontol A Biol Sci Med Sci, 2008, 63(10): 1076-1081.

[36] LAU Y C, GUO R X. A review on current osteoporosis research: With special focus on disuse bone loss $[\mathrm{J}]$. J Osteoporos, 2011, 2011: 293808

[37] REIDY P T, LINDSAY C C, MCKENZIE A I, et al. Aging-related effects of bed rest followed by eccentric exercise rehabilitation on skeletal muscle macrophages and insulin sensitivity $[\mathbf{J}]$. Exp Gerontol, 2018, 107: 37-49

[38] National Pressure Ulcer Advisory Panel. NPUAP 2016 Staging Consensus Conference. NPUAP pressure injury stages $[\mathrm{EB} / \mathrm{OL}]$. (2016-04-13)[2019-09-15]. https://www.npuap.org/.

[39] OTERO T M N, CANALES C, YEH D D, et al. Vitamin D status is associated with development of hospital-acquired pressure injuries in critically ill surgical patients $[\mathrm{J}]$. Nutr Clin Pract, 2018, 34 (1): 142-147.

[40] KAYSER S A, VANGILDER C A, AYELLO E A, et al. Prevalence and analysis of medical device-related pressure injuries: Results from the international pressure ulcer prevalence survey $[\mathbf{J}]$. Adv Skin Wound Care, 2018, 31 (6): 276-285.

[41] RUSSELL C, FITZGERALD M H, WILLIAMSON P, et al. Independence as a practice issue in occupational therapy: The safety clause $[\mathrm{J}]$. Am J Occup Ther, 2002, 56 (4): 369-379.

[42] CLARK F. Reflections on the human as an occupational being: Biological need, tempo, and temporality $[\mathrm{J}]$. J Occup Sci, 1997, 4 (3): $86-92$

[43] WILCOCK A A. Reflections on doing, being and becoming [ $\mathrm{J}]$. Aust Occup Ther J, 1999, 46 (1): 1-11.

[44] American Occupational Therapy Association. Occupational Ther- 
apy: Improving function while controlling costs $[\mathrm{EB} / \mathrm{OL}]$. (201904-15) [2019-09-05]. https://www.aota.org/About-OccupationalTherapy/Professionals.aspx.

[45] Occupational therapy practice framework: Domain and process (3rd ed.) $[\mathbf{J}]$. Am J Occup Ther, 2014, 68 (S1): S1-S48.

[46] Scope of Practice $\lceil\mathbf{J}$. Am J Occup Ther, 2014, 68 (S3): S34-S40.

[47] World Federation of Occupational Therapy [EB/OL].(2019-02-06) [2019-09-20]. https://wfot.org/ about

[48 CHRISTIANSEN C H, HAMMECKER C L. Self-care [M]// BONDER B R, WAGNER M B. Functional performance in older adults. Philadelphia: F. A. Davis, 2001: 155-175

[49] BLAGA L, ROBERTSON L. The nature of occupational therapy practice in acute physical care settings $[\mathbf{J}]$. New Zealand $\mathbf{J}$ Occup Ther, 2008, 55 (2): 11-18.

[50] ROBERTSON L. BLAGA L. Occupational therapy assessments used in acute physical care settings $[\mathbf{J}]$. Scand J Occup Ther, 2013, 20(2): 127-135

[51] HAMBY J Altered mental status [M]//SMITH-GABAI H, HOLM $S$ E. Eds. Occupational therapy in acute care. 2nd ed. Bethesda, MD: AOTA Press, 2017: 561-570.

$52]$ SHOTWELL M, JOHNSON K, MIRANDA-FLECHA I. Evaluation of acute care patients [M]//SMITH-GABAI H, HOLM S E. Eds. Occupational therapy in acute care. 2nd ed. Bethesda, MD: AOTA Press, 2017: 37-61.

[53] American Occupational Therapy Association. Selected assessment tools for occupational therapy reporting of outpatient functional data (g-codes and modifiers) to the Medicare program [EB/OL]. (2013-04-15) [2019-09-10]. https://www.aota.org/ /media/Corporate/Files/Advocacy/Reimb/News/AOTAG-CodeChart2013. pdf.

[54] LELAND N E, CRUM K, PHIPPS S, et al. Advancing the value and quality of occupational therapy in health service delivery $[\mathrm{J}]$. Am J Occup Ther, 2015, 69(1): 6901090010pl-7.

[55] ROBERTS P S. ROBINSON M R. Occupational therapy's role in preventing acute readmissions $[\mathrm{J}]$. Am J Occup Ther, 2014, 68(3): $254-259$

[56] CAPEZUTI E A, BOLTZ M, KIM H. Geriatric models of care $[\mathrm{M}] / /$ ROSENTHAL R A, ZENILMAN M E, KATLIC M R. Eds. Principles and practice of geriatric surgery. 2nd ed. New York: Springer, 2011: 253-266.

[57] TIMMER A J, UNSWORTH C A, TAYLOR N F. Occupational therapy inpatient rehabilitation interventions with deconditioned older adults following an acute hospital admission: A Delphi study [J]. Aust Occup Ther J, 2015, 62 (1): 41-49.

[58] KORTEBEIN P. Rehabilitation for hospital-associated deconditioning $[\mathbf{J}]$. Am J Phys Med Rehabil, 2009, 88(1): 66-77.

[59] HOLM S E. Early mobility and rehabilitation [M]//SMITHGABAI H, HOLM S E. Eds. Occupational therapy in acute care. 2nd ed. Bethesda, MD: AOTA Press, 2017: 663-672.

[60] MANINI T M, HONG S L, CLARK B C. Aging and muscle: A neuron's perspective $[\mathbf{J}]$. Curr Opin Clin Nutr Metab Care, 2013, 16(1): 21-26.

[61] DEPALMA G, XU H, COVINSKY K E, et al. Hospital readmissions among older adults who return home with unmet need for ADL disability [J]. Gerontologist, 2013, 53(3): 454-461.

[62] ROGERS A T, BAI G, LAVIN R A, et al. Higher hospital spending on occupational therapy is associated with lower readmission rates $[\mathrm{J}]$. Med Care Res Rev, 2017, 74(6): 668-686.

[63] EYERS L, UNSWORTH C A. Occupational therapy in acute hospitals: The effectiveness of a pilot program to maintain occupational performance in older clients $[\mathrm{J}]$. Aust Occup Ther $\mathrm{J}$, 2005, 5(3): 218-224.

64] American Physical Therapy Association. Scope of Physical Therapist Practice [EB/OL]. (2019-03-20) [2019-10-12]. http://www. apta.org/ ScopeOfPractice/.

65] American Physical Therapy Association. Move forward. Physical Therapy brings movement to life [EB/OL]. (2019-04-30) [201910-13]. https://www.moveforwardpt.com/Default.aspx.

66] American Physical Therapy Association. Guide to Physical Therapist Practice 3.0 [EB/OL]. (2014-05-12) [2019-10-15]. http:// guidetoptpractice.apta.org/.

67] MASLEY P M, HAVRILKO C, MAHNENSMITH M R, et al. Physical therapist practice in the acute care setting: A qualitative study $[\mathrm{J}]$. Phys Ther, 2011, 91 (6): 906-922.

68 GREENWOOD K, STEWART E, MILTON E, et al. Core competencies for entry-level practice in acute care physical therapy
C/OL]//Academy of Acute Care Physical Therapy-APTA Minimum Skills Task Force, 2015. (2015-03-15)[2019-04-30]. https: //cdn.ymaws.com/www. acutept.org/resource/resmgr/docs/2015 PT-core-competencies.pdf.

[69 ] DROLET A, DEJULIO P, HARKLESS S, et al. Move to improve: The feasibility of using an early mobility protocol to increase ambulation in the intensive and intermediate care settings $[\mathbf{J}]$. Phys Ther, 2013, 93 (2): 197-207.

[70] WOOD W, TSCHANNEN A, TROTSKY A, et al. A mobility program for an inpatient acute care medical unit $[\mathbf{J}]$. Am J Nurs, $2014,114(10): 34-40$

[71] SAUNDERS C L, BRENNAN J A. Achieving high reliability with people, processes, and technology $[\mathrm{J}]$. Front Health Serv Manage, 2017, $33(4): 16-25$

[72] BODENHEIMER T, SINSKY C. From triple to quadruple aim: Care of the patient requires care of the provider $[\mathbf{J}]$. Ann Fam Med, 2014, 12 (6): 573-576

[73] PASHIKANTI L, VON AH D. Impact of early mobilization protocol on the medical-surgical inpatient population: An integrated review of literature $[\mathbf{J}]$. Clin Nurse Spec, 2012, 26 (2): 87-94.

[74] KALISCH B J, LEE S, DABNEY B W. Outcomes of inpatient mobilization: A literature review [J]. J Clin Nurs, 2014, 23 (11/12): 1486-1501

75] PEDERSEN M M, BODILSEN A C, PETERSEN J, et al Twenty-four-hour mobility during acute hospitalization in older medical patients $[\mathbf{J}]$. J Gerontol A Biol Sci Med Sci, 2013, 68 (3): 331-337.

[76] MUDGE A M, MCRAE P, MCHUGH K, et al. Poor mobility in hospitalized adults of all ages [J]. J Hosp Med, 2016, 11 (4): 289291.

[77] LIN Y C, YEH M C, CHEN Y M, et al. Physical activity status and gender differences in community-dwelling older adults with chronic diseases [J]. J Nurs Res, 2010, 18 (2): 88-97.

[78 ] MALONE D, RIDGEWAY, NORDON-CRAFT A, et al. Physical therapist practice in the intensive care unit: Results of a national survey $[\mathbf{J}]$. Phys Ther, 2015, $95(10):$ 1335-1344.

79] BROWN C J, FRIEDKIN R J, INOUYE S K. Prevalence and outcomes of low mobility in hospitalized older patients $[\mathbf{J}]$. J Am Geriatr Soc, 2004, 52 (8): 1263-1270.

[80] SHADMI E, ZISBERG A. In-hospital mobility and length of stay [J]. Arch Intern Med, 2011, 171 (14): 1298.

[81] ANDREWS A W, FOLGER S E, NORBET S E, et al. Tests and measures used by specialist physical therapists when examining patients with stroke $[\mathrm{J}]$. J Neurol Phys Ther, 2008, 32 (3): 122128.

[82 ] JETTE D U, BACON K, BATTY C, et al. Evidence-based practice: Beliefs, attitudes, knowledge, and behaviors of physical therapists $[\mathrm{J}]$. Phys Ther, 2003, 83 (9): 786-805.

[83] POTTER K, FULK G D, SALEM Y, et al. Outcome measures in neurologic physical therapy practice $[\mathbf{J}]$. J Neurol Phys Ther, 2011, 35 (2): $57-64$.

[84] SULLIVAN J E, ANDREWS A W, LANZINO D, et al. Outcome measures in neurological physical therapy practice $[\mathbf{J}]$. J Neurol Phys Ther, 2011, 35 (2): 65-74.

[85] MCDONNELL B, STILLWELL S, HART S, et al. Breaking down barriers to the utilization of standardized tests and outcome measures in acute care physical therapist practice: An observational longitudinal study [J]. Phys Thery, 2018, $98(6)$ : $528-538$

[86] LIN M, HWANG H F, HU M H, et al. Psychometric comparisons of the timed up and go, one-leg stand, functional reach, and Tinetti balance measures in community-dwelling older people [J]. J Am Geriatr Soc, 2004, 52 (8): 1343-1348.

[87 ] HARADA N D, CHIU V, STEWART A L. Mobility-related function in older adults: assessment with a 6-minute walk test $[\mathbf{J}]$. Arch Phys Med Rehabil, 1999, 80 (7): 837-841.

[88 ] American Physical Therapy Association. Edge Task Force, PT Now Editors [EB/OL]. (2011-08-25) [2019-09-18]. https://www. movefor wardpt.com/resources/detail/189c5f97-0511-47e9-acc6b19e9756 2e48.

[89] SONG Z, SHI J. Rue Zhongyi Kungfu Rue De Jiben Guandian [J]. J Chin Trad Med, 2007, 48 (7): 581-582.

[90 ] JONES A, SKINNER M A. The current status of Physical Therapy in China $[\mathbf{J}]$. Chin J Rehab Med, 2013, 28 (6): 493-501.

[91] SHI Y, HOWE T H. A survey of occupational therapy practice in Beijing, China $[\mathrm{J}]$. Occup Ther Int, 2016, 23 (2): 186-195. 


\title{
美国的急性医疗实践:作业治疗和物理治疗 在早期康复中的作用
}

\author{
Suzanne E. Holm ${ }^{1,2}$, Kelly Nelson², Angela Patterson ${ }^{2}$ \\ 1 瑞吉斯大学,丹俳,科罗拉多州 80221 ,美国; \\ 2 克霄顿大学, 奥马哈, 内布拉斯加州 68178 ,美国
}

摘要 对早期康复(ER) 中作业治疗 (OT) 和物理治疗 (PT) 的模式和趋势, 以及美国的康复治疗师特别是作 业治疗师(OTs) 和物理治疗师(PTs) 在 ER 中发挥的作用进行了全面综述。首先概述与卧床休养和制动不良 后果相关的研究, OT 和 PT 技术能够最大限度地减少不良后果并通过 $\mathrm{ER}$ 来优化功能; 然后以作业为基础和 以运动为重点探讨康复在减少再入院率和提高患者和家庭满意度方面的作用; 最后分析中国传统 OT 和 PT 的常规治疗, 以及其在 ER 中遇到的挑战和对临床疗效的影响。ER 是在急性医疗过程中针对有康复、安全 或社区支持需求的患者以快速的方式启动治疗服务。在患者遭受损伤、疾病后, ER 可以改善患者的作业表 现和提高其参与活动和运动的能力, 防止其功能进一步变失。在快速过渡的医疗环境中, OT 和 PT 的目标是 促进患者的功能恢复, 从而改善其康复状况并防止残疾的加重和功能的丧失。在美国,联邦法规、医疗政策、 财政限制以及住院时间缩短的规定都要求治疗师全面、高效地推进 ER。同时, ER 必须及时、高效地带来积 极的变化,通过患者的参与来实现患者及其家属所确认的最必要治疗目标, 并使患者成功地过渡到家庭或 其他环境中。ER 不仅改善患者的功能, 而且还能够降低不良后果和意外风险。医院获得性疾病(HAC) 是患 者在住院期间发生的疾病, 患者在卧床休养、制动或身体受到限制时发生 HAC 的风险会增加。患者长期处 于危重疾病、外伤或手术状态下会导致其系统性机能减退, 从而降低患者的功能能力、损害其认知能力、削 弱其心理承受力并增加患者抑郁和焦虑症的发生率。通过 ER 中 OT 和 PT 康复干预措施能够最大限度地 降低患者的不良健康状况、损伤和残疾的风险,同时促进其功能恢复。针对每个康复专业的角色和职责, 美国 的 OTs 可以提升患者的作业表现和对日常工作、角色、习惯和生活的参与能力。通过参与, OT 能够改善患 者的整体健康、幸福感以及在家庭和社区中的独立性。除了提供直接治疗服务外, OTs 还能评估并对具体的 任务和环境的改变提出建议。为了患者获得更大独立性, OTs 的干预集中在代偿技术如通过改变任务或环 境来促进作业治疗, 以及补救技术如康复。PT的重点是促进和改善患者的活动和运动能力, 增强其功能、幸 福感、整体健康和生活质量。PTs 能够促进患者的最佳活动能力, 使患者实现更大限度的独立性和自主性, 并 且恢复或增强其功能水平。对患有或可能出现的与骨骼肌肉、神经肌肉、心血管、肺和皮肤系统相关损伤、活 动受限和参与受限的患者都可以通过 PT 进行治疗。然而, 目前美国的急性医疗制度往往不支持和满足患者 强烈的康复需求，进行持续康复治疗的患者通常要求转移到其他医疗机构实施急性后护理。在美国设立了 多种级别的急性后护理,包括有专业技术要求的护理机构、康复医院、长期急性护理医院、疗养院、诊所、家 庭护理和私人护理等服务。而在中国, 患者可以选择延长住院时间,这为 OT 和 PT 提供了更多康复治疗的 机会。OT和 PT 的目的是恢复患者身体活动能力、增加其肢体活动度并改善其功能, 以便患者能够早日回 归家庭。但是由于中国的文化、传统和习俗的影响, 患者的康复重点很少是通过自我照顾来提高其独立性, 而家庭成员却有责任为患者提供更多的照顾。因此, 这属于典型的支持性家庭动态, 即家庭成员每天都处于 康复干预中, 帮助患者进行治疗性锻炼和理疗。在患者出院后, 其家庭的护理负担会加重, 尤其是未接受过 康复教育的家庭。目前在中国,包括 $\mathrm{OT}$ 和 PT 在内的康复专业处于良好的成长和发展形势, 而从国际视野 了解 OT 和 PT 在急性护理中的独特作用, 不仅通过康复服务, 而且更为重要的是通过关注患者、家庭和社 区来改善全球的健康状况。在急性护理环境中, ER 是改善患者的健康和提高其幸福感, 并使患者能够早日 重返家庭和社区的有效途径, 而 OTs 和 PTs 在 ER 中发挥重要的作用。

关键词医院;康复;作业治疗;物理治疗;卧床休养;临床决策

DOI : 10.3724/SP.J.1329.2020.03014 